\title{
Female southern right whales Eubalaena australis: Are there reproductive benefits associated with their coastal distribution off South Africa?
}

\author{
Simon H. Elwen ${ }^{1,2, *}$, Peter B. Best ${ }^{1}$ \\ ${ }^{1}$ Mammal Research Institute, University of Pretoria, Pretoria 0002, South Africa \\ ${ }^{2}$ Present address: MRI Whale Unit, c/o South African Museum, PO Box 61, Cape Town 8000, South Africa
}

\begin{abstract}
Predictability in both meso- and microscale distribution of southern right whale Eubalaena australis females off the coast of South Africa is attributed to maternal philopatry, as well as favourable environmental conditions (calm water, generally shallow sloping, sedimentary sea bed) conducive to reduced energy consumption and a lowered risk of injury for both cows and calves. Spatial differences in reproductive success were compared between favoured (nursery) and nonfavoured (non-nursery) areas and related to environmental differences in those areas. Reproductive success was inferred from analysis of calving intervals $(3 \mathrm{yr}=$ successful, 2 and $4 \mathrm{yr}=$ unsuccessful; $\mathrm{n}=808$ calving events). Resighting rates as well as differences in distribution between experienced cows ( 3 or more calves) and inexperienced cows ( 1 or 2 calves) were also analysed. Less experienced cows were found to have significantly more unsuccessful calving intervals than experienced cows. No relationship was found between calving success and spatial distribution using calving interval analysis. Significant spatial differences in stranding rates of neonatal calves strongly suggest higher rates of calf mortality in areas dominated by non-cows, independent of environmental conditions. Social structure within wintering grounds was concluded to be more important than previously thought and potentially as important as environmental conditions for calf survival.
\end{abstract}

KEY WORDS: Eubalaena australis $\cdot$ Reproductive success $\cdot$ Age $\cdot$ Calving interval $\cdot$ Environmental factors $\cdot$ Social structure $\cdot$ Stranding

\section{INTRODUCTION}

Southern right whale cows exhibit philopatry to their coast of birth and (to a lesser degree) particular bays (Best 2000a). This philopatry may be at least partly responsible for the highly predictable distribution pattern that both cow-calf pairs and unaccompanied whales have shown along the South African coast since 1969 (Best 1981, 1990a, 2000a). The distribution is segregated generally into 3 concentration areas: $\mathrm{St}$ Sebastian Bay, De Hoop and Walker Bay, the first 2 of which are dominated by cow-calf pairs, and the third by whales without calves (here called 'unaccompanied whales'), although both classes of whales can be found in any of the 3 areas, and many whales fall outside these main concentration sites. As well as philopatry, it was suggested that the greater preference exhibited by whales for certain areas may be related to particular environmental features (Best 2000a).

It has been shown (Elwen \& Best 2004a) that the majority of right whales along the South African coast occupy environmentally similar areas. The 3 main areas of right whale concentration are all reasonably protected from open ocean swell and prevailing winds of the season, and have predominantly sandy shores and substrates. Cows with calves occur significantly closer to shore and in shallower water than unaccompanied whales (Elwen \& Best 2004a). The benefits of calm water are believed to be mainly that of energy conservation by the calves (Corkeron \& Connor 1999), which are weak swimmers during their early life stages (Thomas \& Taber 1984). Sandy bottoms are thought to 
serve primarily for reduction of injury compared to rocky bottoms, especially for calves in very shallow water. The sandy bottoms and proximity to shore also have potential acoustic benefits by reducing and/or masking any noises by the cow or calf from potential killer whale predators (Würsig \& Würsig 1979).

Because the majority of whales occupy environmentally similar areas, and occur mostly within a comparatively small range, it was felt that there could be some measurable reproductive or survival benefit associated with using these areas. Since 1979, photography of cows with calves for individual identification has been carried out annually (Best 1981, 1990b, 2000a). The ability to individually identify right whales has allowed inter alia for the collection of data on return rates of individual cows to particular areas, movements of individual animals, inter-calf intervals and age at first parturition for those animals identified both as calves and mothers (Best 2000a, Best et al. 2001). In this paper, the observed calving intervals of individual females have been used as an index of reproductive success. In addition, the incidence of stranded neonates has been used as an index of neonatal survival. Both indices have been examined in relation to coastal distribution.

\section{MATERIALS AND METHODS}

Since 1979, aerial surveys for photography have been performed once a year in early to mid-October and have covered the area between Muizenberg (False Bay) and Nature's Valley (Plettenberg Bay) (Fig. 1). For details of the survey procedures see Best (1990b). Because surveys pre-dated the adoption of global posi-

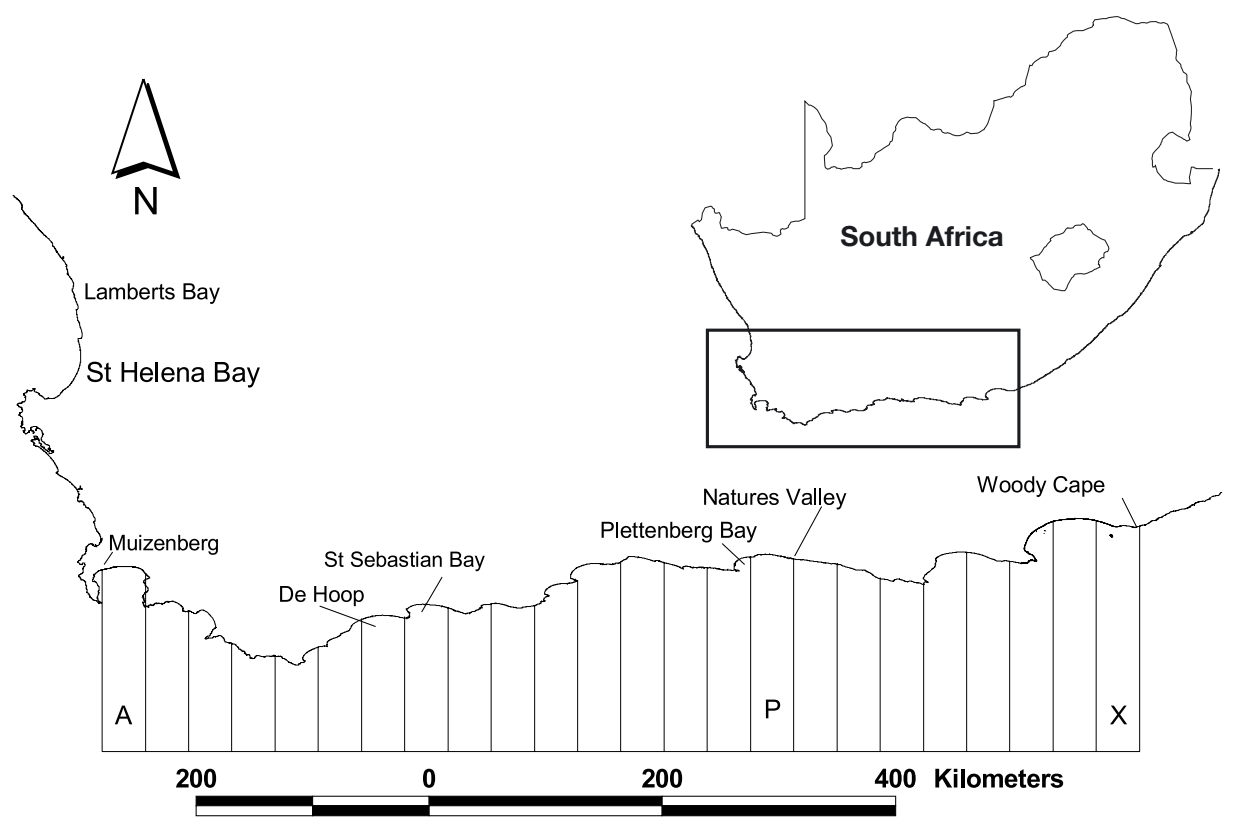

tioning systems, positions of animals were described relative to adjacent landmarks, and were thus not very precise. For analysis, the coastline was divided into 'bins' 20 min of longitude wide labelled from west to east as A to X, after Best (2000a) (Fig. 1). For the purpose of this study, whale positions and movements along the coast have been described using these bins ( $Q$ to $X$ being excluded because they were only covered by fixed-wing surveys with no photography of animals). Data through to the 1999 survey have been included in this analysis.

Because the distribution of right whales is highly concentrated in some areas but not others, data outside of the 4 most densely populated bins $(\mathrm{C}, \mathrm{F}, \mathrm{G}, \mathrm{H})$ were summed to increase sample size. These low density bins were split into 2 categories: bins containing potentially attractive calving areas that currently have low density (A, B, D, E, K, L, O) and bins that have very low potential attractiveness for cows (I, J, M, N), based on conclusions of Elwen \& Best (2004a,b). These grouped areas are referred to as 'GLD' (good bin, low density) and 'Unatt.' (unattractive areas), respectively.

The Mammal Research Institute's data set of all known cetacean strandings along the Western Cape coast from 1963 to mid-2000 was available for study. The positions of all right whale calves (animals $<8.0 \mathrm{~m}$ in length) reported stranded (live or dead, none reported with obvious anthropogenic causes) during this time period were noted and assigned to equivalent survey bins. Animals stranded on the west coast were grouped together because whale density here is considerably lower than on the south coast and any further spatial breakdown would reduce samples to an unusable size (see Best 2000a). The west coast in this analysis is regarded as that area west of the standard survey range, from Muizenberg around the Cape Peninsula as far north as St Helena Bay (Fig. 1). Data generated from all the aerial surveys (of the standard survey area) were used to create expected numbers of stranded calves based on the average proportion of cow-calf pairs photographed

Fig. 1. Southern and southwestern coast of South Africa showing place names and the surveyed region of the coast with an indication of the longitudinal bins used in analysis. Fixed wing surveys for right whales (1969-1987) covered Bins A-X, helicopter surveys (1979-2000) covered Bins A-O 
in each bin. Because of the relative scarcity of survey effort on the west coast, the number of expected strandings on the west coast was based on the proportion of cow-calves found in this entire area $(6.6 \%)$ as described by Best (2000b). The actual and expected distributions of the 34 stranded calves were compared using a log-likelihood test, as chi-squared assumptions were violated due to small sample sizes in most areas (Zar 1984). Calf strandings were similarly summed into GLD and Unatt. bins as for calving interval analyses.

Totals of 1397 calving events, 1012 inter-calf intervals and 34 stranded dead calves were available for analysis. The normal inter-calf interval of right whales is believed to be $3 \mathrm{yr}$ (Knowlton et al. 1994, Best et al. 2001, Burnell 2001) but observed calving intervals between 2 and 21 yr (P.B.B. unpubl. data) have been reported. The occurrence of a 2 yr calving interval is thought to represent the loss of a neonate, followed by ovulation of the cow after $1 \mathrm{yr}$ rather than 2 (Burnell 2001), since a cow does not have to bear the energetically high cost of lactation (Lockyer 1981). Interpretation of $4 \mathrm{yr}$ calving intervals is less clear and differs between authors. Burnell (2001) suggests that a proportion of the population may calve normally at a $4 \mathrm{yr}$ interval due to the high proportion of such intervals $(14 \%, \mathrm{n}=57)$ in the Australian population. Knowlton et al. (1994) interpret a 4 yr interval in North Atlantic right whales to indicate loss/abortion of a putative second calf early in a pregnancy, thus the cow does not have to bear the cost of either pregnancy or lactation, and effectively has 2 resting years between successive calves. Alternately, in situations where food is scarce, cows may require 2 resting years between calves in order to regain the required body condition. However, the occurrence of $4 \mathrm{yr}$ calving intervals is much lower in the South African population $(8 \%, \mathrm{n}=808)$ than either the Australian or North Atlantic populations, and in this study 4 yr calving intervals are assumed to represent the loss of 2 successive calves with the second calf going undetected. Yet this assumption is first tested by examining the incidence of $4 \mathrm{yr}$ intervals with age. A calving interval of 3 yr was classified, therefore, as 'successful', and intervals of 2 and $4 \mathrm{yr}$ as 'unsuccessful'; calving intervals longer than 4 yr were ignored due to difficulties with interpretation (thereby reducing the sample to 808 inter-calf intervals).

Based on the assumption that some areas may be more suitable as calving grounds than others and result in more successful calvings, the occurrence of successful and unsuccessful calving intervals was compared for different areas along the coast. Furthermore, because it was possible for cows to change areas after having a successful or unsuccessful calving interval, the bin occupied after successful and unsuccessful calving intervals was also analysed.
The tendency for a cow to be photographed with successive calves in the same bin ('stay') or different bins ('move') was also analysed in relation to the bins concerned. Site fidelity was analysed under 2 definitions, the strict definition being a resighting of a cow with its next calf in the same bin, and the broad definition a resighting in the same or an adjacent bin (as used by Best 2000a). As a measure of the experience of cows, animals were classified as 'inexperienced' if they were photographed for the first or second time with a calf, and 'experienced' if they were photographed with their third or subsequent calf. If 'inexperienced' mothers are less successful than experienced mothers, they might be expected to occupy substandard habitat or different bins than experienced mothers. The distribution of experienced and inexperienced cows per bin as well as the tendency for cows to 'move' or 'stay' at each level of experience were analysed. In the beginning of the survey series, all cows were by definition 'inexperienced' since they had never been seen before. To compensate for this, only data from 1988 onwards (or after 3 possible calving intervals) were analysed; as with the modelled re-sighting rate (76 to $81 \%$, Best et al. 2001), there would be a $99.1 \%$ probability that a cow would have been photographed at least once if it had given birth 3 times in the interim. This means that after 1988 a cow seen for the first time with a calf would most likely have been an actual inexperienced individual. All comparisons in the above analysis were done using a chi-squared test to compare actual distributions with those expected from the null hypothesis of no difference between any of the tested factors.

\section{RESULTS}

\section{Using 2 and 4 yr calving intervals as indicators of reproductive failure}

The frequencies of 2, 3 and 4 yr intervals following the first, second and third to fifth recorded calves are shown in Table 1. Both 2 and 4 yr intervals show a similar pattern when compared to 3 yr calving intervals, in that the proportions of such intervals are highest after the first recorded calf than after subsequent calvings $\left(\mathrm{chi}^{2}=201.25, \mathrm{p}<0.005, \mathrm{df}=3\right.$, for $2 \mathrm{yr}$ and $\mathrm{chi}^{2}=6.98$, $\mathrm{p}=0.008, \mathrm{df}=3$, for $4 \mathrm{yr}$ intervals). Consequently, we opted to use the incidence of 2 and 4 yr calving intervals together as an indication of reproductive failure and have summed them in all other analyses.

\section{Calving success and coastal distribution}

No pattern was found to indicate a higher proportion of more successful calvings in some bins rather than 
others $\left(\mathrm{chi}^{2}=4.63, \mathrm{p}=0.46, \mathrm{df}=11\right)$ (Fig. 2a). Nor were cows more likely to occupy certain areas rather than others after having either a successful or unsuccessful calving interval $\left(\mathrm{chi}^{2}=0.88, \mathrm{p}=0.97, \mathrm{df}=11\right)$. Cows initially seen in the 4 main bins (highest occupancy areas) were more likely to be resighted with their subsequent
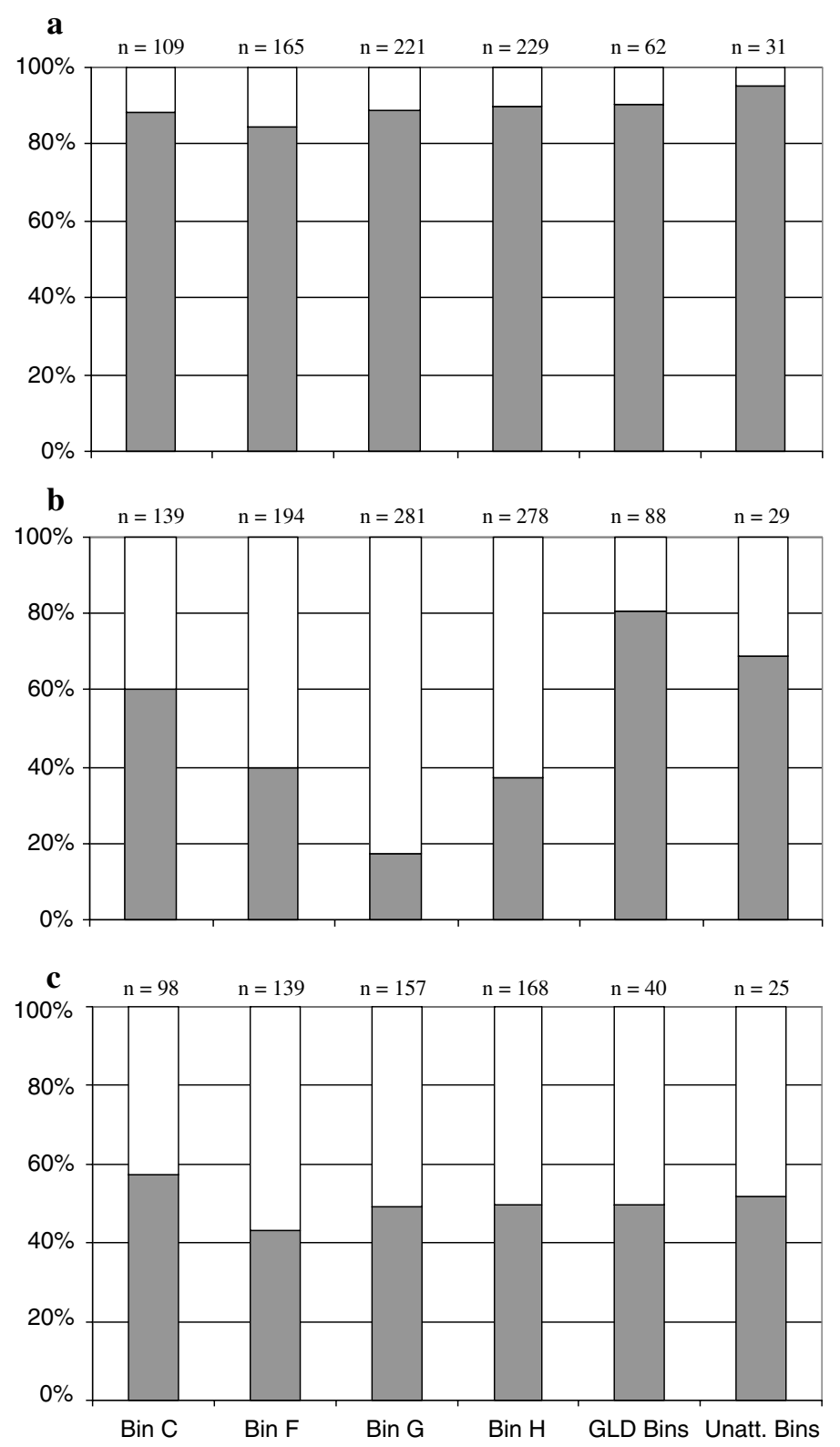

Fig. 2. Eubalaena australis. (a) Comparison of unsuccessful (white) and successful (grey) right whale calving intervals (shown as proportions) between each of the longitudinal bins (or groups of bins) analysed on the South African coast. (b) Proportion of right whale cows staying (white) or moving (grey) using the broad definition, following calving in a specific longitudinal bin or group of bins. (c) Proportion of experienced (3 or more calves) (white) and inexperienced (grey) right whale cows found in each longitudinal bin or group of bins calves ('stay') within the same bin than in the rest of their range $\left(\mathrm{chi}^{2}=36.1, \mathrm{p}<0.001, \mathrm{df}=11\right)$. This pattern was further accentuated when a 'stay' was broadened to include an adjacent bin $\left(\mathrm{chi}^{2}=156.0, \mathrm{p}<0.001\right.$, $\mathrm{df}=11$ ) (Fig. $2 \mathrm{~b}$ ) and was shown more strongly in the nursery areas (Bins $\mathrm{F}-\mathrm{H}$ ) than any other bins.

Cows were not found to move or stay more after either a successful or unsuccessful calving interval when using the broad definition of 'stay' $\left(\mathrm{chi}^{2}=2.38\right.$, $p=0.123, d f=3$ ). However, they were more likely to move after a successful calving interval when using the strict definition of 'stay' $\left(\mathrm{chi}^{2}=311.5, \mathrm{p}<0.001, \mathrm{df}=3\right)$.

\section{Reproductive experience and coastal distribution}

No differences in the ratios of experienced and inexperienced cows were found between the different bins for the post-1988 distribution $\left(\mathrm{chi}^{2}=4.62, \mathrm{p}=0.464\right.$, $\mathrm{df}=11$ ) (Fig. 2c). Bin F (De Hoop) had the highest proportion of experienced cows $(56.8 \%)$ while Bin C (Walker Bay) had the lowest (42.8\%) (Fig. 2c). The number of times a cow had calved had no apparent influence on their tendency to remain in or move from the particular bin where they were first photographed, when using either the strict or broad definition of 'stay' (strict: $\mathrm{chi}^{2}=0.75, \mathrm{p}=0.944, \mathrm{df}=9$; broad: $\mathrm{chi}^{2}=3.54$, $\mathrm{p}=0.472, \mathrm{df}=9$ ); nor was any pattern evident for any change in behaviour with experience.

\section{Neonatal mortality and coastal distribution}

The raw distribution of all stranded calves per bin in the Western Cape is shown in Fig. 3a. When grouped for analysis, the distribution of stranded calves is significantly different to that predicted from the distribution of cow-calf pairs along the coast $(\mathrm{G}=21.453, \mathrm{p}<0.05$, $\mathrm{df}=11)($ Fig. 3b). The expected and observed distributions were very similar in Bins $F$ and $G$, while fewer animals than expected stranded in St Sebastian Bay (Bin H). In all other areas more calves stranded than would be expected from the number of cows present; this is most noticeable in Walker Bay and along the west coast, but is also evident for low density, potentially attractive calving areas.

\section{DISCUSSION}

The distribution of cow-calf pairs along the South African coast is clearly biased toward certain areas (Best 1990a, Elwen \& Best 2004a). While Best (1981, 1990a) reported that some areas (Bins F, G, H) were used as nurseries, he found that another area (Bin C) 
Table 1. Eubalaena australis. Number (and percentages) of 2, 3 and 4 yr calving intervals observed in southern right whales off South Africa following successive calves

\begin{tabular}{|lcccccc|}
\hline Interval & Calf 1 & Calf 2 & Calf 3 & Calf 4 & Calf 5 & Calves 3-5 \\
\hline $3 \mathrm{yr}$ & 257 & 179 & 144 & 81 & 45 & 270 \\
& $(84.3 \%)$ & $(89.1 \%)$ & $(92.9 \%)$ & $(93.1 \%)$ & $(91.8 \%)$ & $(92.8 \%)$ \\
$2 \mathrm{yr}$ & 14 & 6 & 5 & 1 & 1 & 7 \\
& $(4.6 \%)$ & $(2.9 \%)$ & $(3.2 \%)$ & $(1.1 \%)$ & $(2.1 \%)$ & $(2.4 \%)$ \\
$4 \mathrm{yr}$ & 34 & 16 & 6 & 5 & 3 & 14 \\
& $(11.1 \%)$ & $(7.9 \%)$ & $(3.9 \%)$ & $(5.8 \%)$ & $(6.1 \%)$ & $(4.8 \%)$ \\
\hline
\end{tabular}
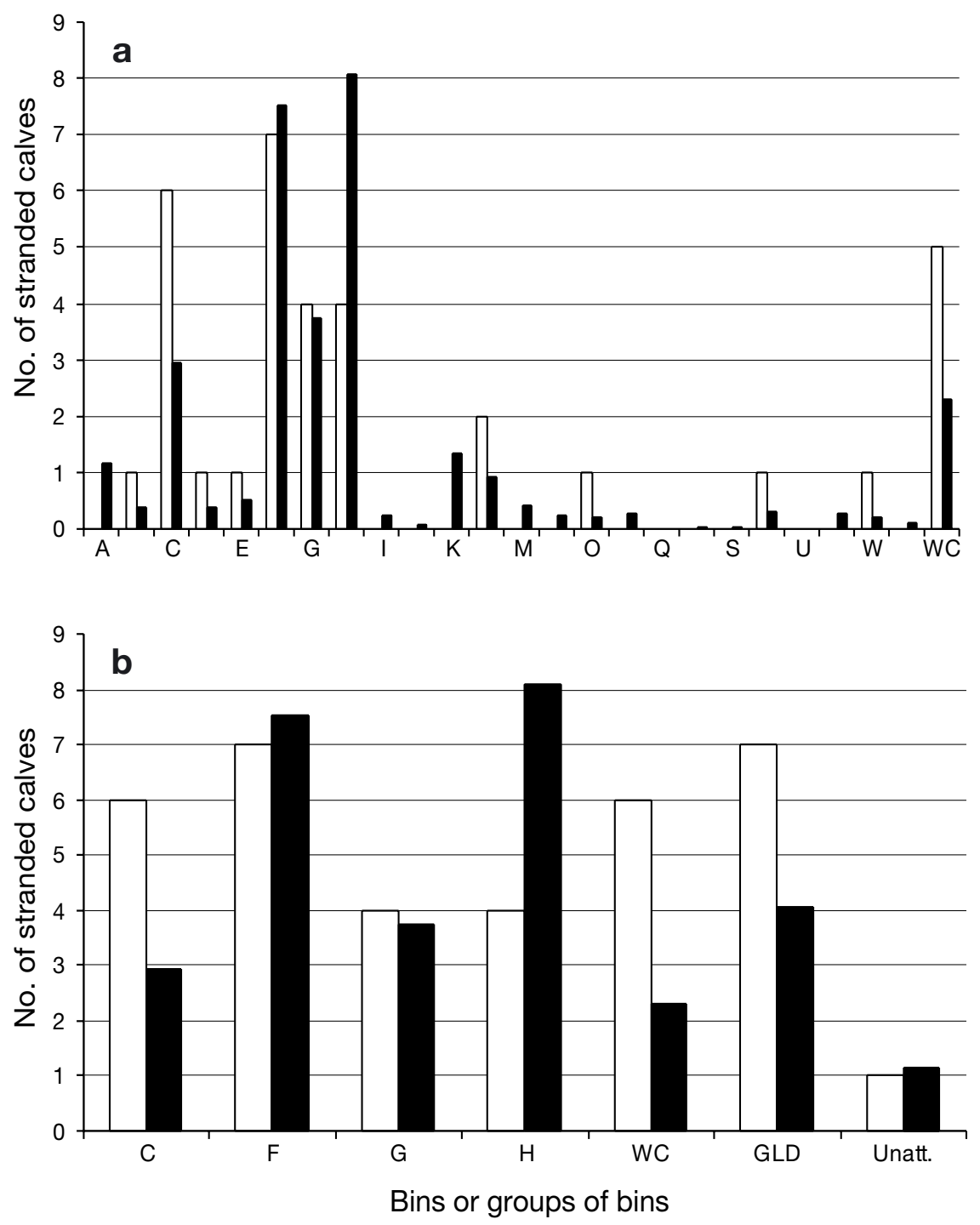

Fig. 3. Eubalaena australis. (a) Observed distribution of all stranded right whale calves (white bars) on the South African southwestern Cape coast, shown per bin, with the west coast (WC) as 1 area. Expected distribution (black bars) based on average distribution of cow-calf pairs over the same period, using aerial survey data. (b) Observed (white bars) and expected (black bars) distribution of stranded right whale calves, as summarised and used in analysis was dominated by unaccompanied whales and may be a 'mating' area. Whale density is much higher in these areas than along the rest of the coast, and this high degree of clumping has a considerable influence on any study of distribution.

The use of calving intervals in this paper as an indicator of reproductive success is supported by the higher proportion of unsuccessful calving intervals occurring in inexperienced mothers. The tendency for reproductive success (measured as either surviving offspring or variations in the sex ratio) to increase with age is a welldocumented phenomenon, predicted by life history theory (Stearns 1992). This pattern has been observed in ungulate artiodactyls (mountain goats) (Côté \& Festa-Bianchet 2001) and both southern (Wilkinson \& van Aarde 2001) and northern elephant seals (Reiter et al. 1981). The phenomenon has previously been suggested as the reason for the small size of most stranded right whale calves, as smaller (and presumably younger) cows have smaller calves (Best \& Rüther 1992). Life history theory predicts that for iteroparous animals with parental care, parental experience increases with age along with reproductive success (Stearns 1992) and older females may offer better care or protection to their young (Reiter et al. 1981). It is not clear whether the higher mortality of firstborn right whales is the result of reduced parental care or physical inadequacies of the calf.

The lack of any spatial pattern associated with successful or unsuccessful calving intervals indicates that there is no reproductive benefit associated with the different areas. However, the data set used for this analysis does have certain limitations that may also influence results. The aerial surveys occurred fairly late into the season to maximise the number of calves seen: because peak calving occurs in August (Best 1994), most calves along the coast would have been born by October. Cows with calves have been shown to move long distances along 
the coast within a season (Burnell \& Bryden 1997, Best 2000a). Thus it is possible that the bin in which a whale is photographed with a calf in October is neither the bin in which the calf was born nor the bin in which it spent its early post-natal period (when calves are at their most susceptible). The late timing of the survey, as well as the instantaneous nature thereof, could thus have considerable influence on the data used here.

With the above proviso, the fact that cows are not preferentially moving to specific areas after having an unsuccessful calving interval (i.e. losing a calf or 2) can be interpreted in 2 ways. Either they do not learn from experience and continue to return to an area where a calf was lost, or there are no reproductive benefits associated with moving to a particular area rather than any other. Since the distribution patterns of these animals have been predictable and stable for as long as the surveys have been run, and the majority of cows have been found to occur in areas that are environmentally similar, there must be some benefit for cows to return to these areas each year.

Best (1990a) showed a net immigration of cow-calf pairs into what he termed the Cape Infanta nursery region (Bins E-I), resulting in a low or zero increase rate of cow-calf pairs throughout the rest of the survey region. This pattern of movement is largely responsible for the higher rates of resightings found in the nursery area by Best (2000a) as well as in this analysis, since cows were more likely to move to this area than away from it. Cows appear to be treating the entire nursery region as 1 area and have been noted to move between its 2 main sub-areas both within and between years (Best 2000a). Best (1990a) only attained a $26.9 \%$ (1979-1987) resight rate for cows in the Walker Bay region (regarded as Bins A-D in this paper), which is considerably lower, despite a broader scale, than the rate attained either in Best (2000a; 1979-1998: 32.3\% strict; $38.5 \%$ broad) or in this paper (1979-1999: $35.5 \%$ strict; $39.6 \%$ broad, Fig. 2 b). The considerable increase in resight rates between the 2 periods reflects the strong increase in importance of the Walker Bay area for cows with calves since the early 1990s (Elwen \& Best 2004a,b).

Best (2000a) suggested that the higher fidelity to the nursery region could be related to environmental characteristics which make this area more attractive for cow-calf pairs. Elsewhere we have shown that although environmental features are important and the majority of animals occur in 'attractive' areas, other environmentally attractive areas occur throughout the survey range with very low whale density (Elwen \& Best 2004a). So although environmental characteristics may be important in a calving area, it is possible that the presence of numbers of other cow-calf pairs is also an important factor, that is not necessarily expressed as increased calving success per se. The 'dilution effect' is one acknowledged benefit of group-living in cetaceans (Connor 2000, Whitehead \& Mann 2000). The aggregation of cow-calf pairs in a nursery area has the dual benefit of reducing the odds of predation per individual calf (Whitehead \& Mann 2000) as well as diluting the occurrence of male harassment that can be fatal to calves (Connor 2000).

The lowest proportional occurrence of stranded calves occurs in St Sebastian Bay, which has been the longest-standing calving area within the nursery region over the last $30 \mathrm{yr}$ (Elwen \& Best 2004a), while strandings in the remainder of the nursery area are close to expected values. The higher than expected number of calf strandings in the rest of the range, particularly along the west coast, could reflect some adverse characteristic in these areas. This characteristic is unlikely to be a feature of the physical environment, such as shelter from wind or swell, nature of substrate, slope of sea floor or presence of river mouths, as Walker Bay, False Bay and several other regions share similar such features with the De Hoop area (Elwen \& Best 2004a).

The areas found to have a higher than expected number of calf strandings are all characterised by having a higher density of unaccompanied whales than cow-calf pairs (Best 2000, Elwen \& Best 2004a). Harassment either of the calf or the mother by other right whales could play a crucial role in the survival of neonatal calves. Records exist of calves being separated from their mothers by other individuals, and cows are thought to purposely avoid the very active socialising behaviours of unaccompanied animals by moving closer to shore (Thomas 1987). It is thus possible that the presence of a high number or proportion of unaccompanied whales is detrimental to the survival of neonatal calves, especially those of inexperienced mothers that may lack the ability to avoid harassment.

This conclusion depends on the assumption that the incidence of reported strandings is representative of the true distribution of mortalities. In reality, currents and the presence of interested observers can influence whether and where a dead calf comes ashore, and whether it is reported, respectively. Furthermore, as almost all the stranded calves in the data set are smaller on average than their contemporaries, they probably died very soon after birth or were stillborn, and may be first-born young of inexperienced mothers (Best \& Rüther 1992). Potentially, their deaths could be the result of factors other than harassment, such as their mothers' lack of care or poor nutritional condition.

Cow-calf pairs have also been noted to segregate from other whales at larger scales both in South Africa (Best 1990b) and Argentina (Payne 1986), and the segregation of cow-calf pairs from unaccompanied 
whales in both longshore and offshore directions (Best 2000a, Elwen \& Best 2004a) suggests there may be a benefit for cows with calves to avoid contact with unaccompanied whales. The higher losses of calves incurred by new mothers indicate that in addition to body condition and cow size, the mother's experience in avoiding or controlling contact with non-mothers could play a crucial role in the survival of neonatal calves. This is probably at its most important in the small Stage 1 calves where, if separated, the calf requires the approach of the mother to re-establish contact (Taber \& Thomas 1982). Since most calves have grown beyond Stage 1 by the time the aerial surveys were performed, it is perhaps not surprising that few correlations were found between reproductive success and coastal distribution.

These findings indicate that the presence of a 'nursery area', where the number of unaccompanied whales is relatively low and the presence of other cow-calf pairs potentially dilutes contact with non-mothers, could be at least as important to cows as being in an environmentally suitable area. Social structure within the nursery area could therefore potentially be of greater importance to reproductive success than previously thought.

Acknowledgements. The authors would like to thank N. Lindenberg and the UCT Geomatics department for help with GIS; the South African Naval Hydrographers office, Council for Scientific and Industrial Research-EMATEK, Institute for Maritime Technology and Marine and Coastal Management for various environmental data, the National Research Foundation for project and bursary support and the World Wide Fund for Nature-SA, The Green Trust, Moby Dick Rum and the other previous sponsors of the aerial surveys (see Best 2000a for full listing). This work was conducted under a series of permits issued to P.B.B. in terms of the Sea Fisheries Act (Act 58 of 1973), Sea Fishery Act (Act 12 of 1988) and the Marine Living Resources Act (Act 18 of 1998). This material is based upon work supported by the National Research Foundation (South Africa) under grant number 2034991.

\section{LITERATURE CITED}

Best PB (1981) The status of right whales (Eubalaena australis) off South Africa, 1969-1979. Invest Rep Sea Fish S Afr 80:1-44

Best PB (1990a) Trends in the inshore right whale population off South Africa, 1969-1987. Mar Mamm Sci 6(2):93-108

Best PB (1990b) Natural markings and their use in determining calving intervals in right whales off South Africa. S Afr J Zool 25:114-123

Best PB (1994) Seasonality of reproduction and the length of gestation in southern right whales (Eubalaena australis). J Zool Lond 232:175-189

Best PB (2000a) Coastal distribution, movements and site fidelity of right whales Eubalaena australis off South Africa, 1969-1998. S Afr J Marine Sci 22:43-55

Best PB (2000b) Comparison of distribution of Southern African right whales (Eubalaena australis) in the nineteenth and twentieth centuries. SC/52/OS11. Submitted to the 52nd meeting of the IWC, Adelaide, 2000

Best PB, Rüther H (1992) Aerial photogrammetry of southern right whales, Eubalaena australis. J Zool Lond 228: 595-614

Best PB, Brandao A, Butterworth DS (2001) Demographic parameters of southern right whales off South Africa. J Cet Res Manag (Spec Iss 2):161-169

Burnell SR (2001) Aspects of the reproductive biology and behavioural ecology of right whales off Australia. J Cet Res Manag (Spec Iss 2):89-102

Burnell SR, Bryden MM (1997) Coastal residence periods and reproductive timing in southern right whales, Eubalaena australis. J Zool Lond 241:613-621

Connor RC (2000) Group living in whales and dolphins. In: Mann J, Connor RC, Tyack PL, Whitehead H (eds) Cetacean societies. University of Chicago Press, Chicago, p 199-218

Corkeron PJ, Connor RC (1999) Why do baleen whales migrate? Mar Mamm Sci 15(4):1228-1245

Côté SD, Festa-Bianchet M (2001) Reproductive success in female mountain goats: the influence of age and social rank. Anim Behav 62:173-181

Elwen SH, Best PB (2004a) Environmental factors influencing the distribution of southern right whales (Eubalaena australis) on the south coast of South Africa I: broad scale patterns. Mar Mamm Sci 20(3):in press

Elwen SH, Best PB (2004b) Environmental factors influencing the distribution of southern right whales ( $E$. australis) on the south coast of South Africa II: within bay distribution. Mar Mamm Sci 20(3):in press

Knowlton AR, Kraus SD, Kenney RD (1994) Reproduction in North Atlantic right whales (Eubalaena glacialis). Can J Zool 72(7):1297-1305

Lockyer C (1981) Estimation of the energy costs of growth, maintenance and reproduction in the female minke whale (Balaenoptera acutorostrata), from the southern hemisphere. Rep Int Whal Comm 31:337-343

Payne R (1986) Long term behavioural studies of the southern right whale (Eubalaena australis). Rep Int Whal Comm (Spec Iss 10):161-167

Reiter J, Panken KJ, LeBoeuf BJ (1981) Female competition and reproductive success in northern elephant seals. Anim Behav 29:670-687

Stearns SC (1992) The evolution of life histories. Oxford University Press, Oxford

Taber S, Thomas P (1982) Calf development and mother-calf spatial relationships in southern right whales. Anim Behav 30:1072-1083

Thomas PO (1987) Social behaviour, habitat use and interspecific interactions of southern right whale (Eubalaena australis) mother-calf pairs. PhD thesis, University of California, Santa Cruz

Thomas P, Taber S (1984) Mother-infant interaction and behavioral development in southern right whales, Eubalaena australis. Behavior 88:42-60

Whitehead H, Mann J (2000) Female reproductive strategies in cetaceans: life histories and calf care. In: Mann J, Connor RC, Tyack PL, Whitehead H (eds) Cetacean societies. University of Chicago Press, Chicago, p 219-248

Wilkinson IS, van Aarde RJ (2001) Investment in sons and daughters by southern elephant seals, Mirounga leonina, at Marion Island. Mar Mamm Sci 17(4):873-887

Würsig B, Würsig M (1979) Behavior and ecology of the dusky dolphin, Lagenorhynchus obscurus, in the South Atlantic. Fish Bull Fish Wildl Serv US 77(4):871-890

Zar JH (1984) Biostatistical analysis. Prentice-Hall, Englewood Cliffs, NJ

Submitted: March 6, 2003; Accepted: November 11, 2003

Proofs received from author(s): March 17, 2004 